\title{
A INFORMAÇÃO E SUAS LEIS: UM PARALELO ENTRE O PENSAMENTO DE RANGANATHAN E O DE MOODY E WALSH
}

THE INFORMATION AND ITS LAWS: A PARALLEL BETWEEN RANGANATHAN'S THINKING AND MOODY AND WALSH

Izabel Lima dos Santos ${ }^{1}$

\section{RESUMO}

Esse trabalho discorre acerca dos paralelismos e dicotomias existentes entre as Leis de Ranganathan (Biblioteconomia) e as Leis da Informação, elaboradas por Moody e Walsh. Para tanto, realizou-se revisão bibliográfica a fim de obter dados que permitissem a contextualização de cada grupo de leis dentro dos cenários para os quais foram pensadas. Em seguida estabelecem-se relações entre elas e demonstram-se maneiras pelas quais o uso conjunto das Leis de Ranganathan e das Leis da Informação pode contribuir para a compreensão do cenário informacional contemporâneo. Conclui reforçando as relações e as possibilidades de ampliação teórica que essa aproximação pode promover.

PALAVRAS-CHAVE: Leis de Ranganathan. Leis da informação. Informação.

\begin{abstract}
This paper argue about the similarities and dichotomies existing between the Five laws of Ranganathan (Librarianship) and the Laws of Information, formulated by Moody's and Walsh. For this purpose, a literature review was carried out in order to obtain data allowing contextualization of each group of laws inside the scenarios for which it was designed. Following settle relations between them and shows up ways in which the combined use of the Five laws of Ranganathan and Information Laws can contribute to the understanding of contemporary informational scenario. Concludes strengthening the relations and theoretical expansion possibilities that this approach can promote.
\end{abstract}

KEYWORDS: Five laws of Ranganathan. Laws of information. Information.

\section{INTRODUÇÃO}

O século XX foi um período de ampla e intensa efervescência nas mais variadas esferas da sociedade. É quase unânime a opinião de que nunca antes em sua trajetória, a humanidade vivenciou um período de crescimento tão acelerado. Inúmeras foram as discussões sociológicas fomentadas por esse crescimento efervescente, mas de um modo geral, pode-se dizer que

A realidade que os conceitos das ciências sociais procuram expressar refere-se às transformações técnicas, organizacionais e administrativas que têm como "fatorchave" não mais os insumos baratos de energia - como na sociedade industrial -

1 Graduada em Biblioteconomia pela Universidade Federal do Ceará. Bibliotecária na referida universidade. E-mail: zbel.lima@gmail.com

Recebido em: 08/02/2015 - Aceito em: 19/08/2015 
mas os insumos baratos de informação propiciados pelos avanços tecnológicos na microeletrônica e telecomunicações. (WERTHEIN, 2000, p.71).

Em meio aos muitos temas e caminhos desbravados nesse período um deles destacouse tanto pela diversidade de abordagens que ensejou, quanto pelo impacto causado pelas pesquisas realizadas a seu respeito. Logicamente que falamos da informação.

A informação está presente na humanidade desde os seus primórdios. Na verdade, pode-se afirmar com certa convicção que uma é inerente a outra. Apesar disso, a informação nem sempre ocupou o centro da arena de fenômenos considerados dignos de reflexão e pesquisa, mas quando passou a fazê-lo, diversas áreas tomaram-na de assalto e não poderia ser diferente, uma vez que a informação é infinitamente multifacetada, ou como diz Wilden (2001 apud ROBREDO, 2003, p. 04)

a informação apresenta-se-nos em estruturas, formas, modelos, figuras e configurações; em ideias, ideais e ídolos; em índices, imagens e ícones; no comércio e na mercadoria; em continuidade e descontinuidade, em sinais, signos, significantes e símbolos; em gestos, posições e conteúdos; em freqüências, entonações, ritmos e inflexões; em presenças e ausências; em palavras; em ações e em silêncios; em visões e em silogismos. É a organização da própria variedade.

Diante de tamanha complexidade várias áreas do conhecimento elaboraram esquemas visando um maior entendimento e, portanto, uma melhor apropriação e uso da informação e dos suportes que a comportam. Cada área trilha caminhos distintos e aborda esse fenômeno de modo peculiar, chegando, portanto, a compreensões próprias e que buscam se adequar da melhor maneira as suas necessidades específicas. Porém, quando se aborda fenômenos tão onipresentes quanto a informação, é de fundamental importância que busquemos estabelecer pontes entre essas compreensões, pois, como nos diz Santillana (1970, p. 19), "uma explicação só é válida, por assim dizer, se ela atua simultaneamente em diferentes níveis. Só neste momento é que a convergência de razões em níveis diversos nos dá a ideia de cosmos."

É importante salientar que a "ideia de cosmos" que se busca nesse trabalho não é, em momento algum, a busca de uma compreensão única do que seja informação, mas sim uma aproximação, e possível diálogo, entre duas das muitas possibilidades de abordagem já existentes acerca desse fenômeno.

As possibilidades de coesão aqui abordadas são referentes às Leis de Ranganathan e às Leis da Informação. As Leis de Ranganathan foram idealizadas pelo matemático e bibliotecário indiano Shiyali Ramamrita Ranganathan e foram expostas ao mundo no livro, considerado um clássico da área, Five laws of Library Science, em 1931. As Leis da Informação foram idealizadas por Daniel Moody e Peter Walsh e apresentadas, em artigo intitulado Measuring The Value Of Information: An Asset Valuation Approach, na sétima Conferência Europeia de Sistemas, em 1999.

Ao longo deste artigo buscamos mostrar que as disparidades - sejam de períodos e áreas em que se originaram, seja de foco e objetivos - existentes entre essas leis não suplantam as convergências e as possibilidades de integração entre elas com a intenção não 
só de uma maior compreensão do fenômeno informacional, mas também de permitir que todos aqueles que lidam com esse fenômeno possuam elementos norteadores mais sólidos para o seu constante trato com a informação.

\section{INFORMAÇÃO: ALGUMAS CONSIDERAÇÕES}

Abordar conceitualmente a informação é ousar adentrar no ainda pouco explorado espectro teórico daquela que, sem sombra de dúvidas, constitui-se na matéria-prima fundamental da sociedade desde tempos imemoriais. Entretanto, apesar de sempre ter estado presente nos diversos tipos de sociedades foi somente no século XX que a informação passou a ser alvo de interesse e investigação de múltiplos e variados campos do conhecimento.

Acerca do recente aumento do interesse pela informação Cardoso (1996, p. 71) diz que

[...] data deste século [o XX] o destaque maior ao termo [informação], desde sua apropriação enquanto fator de produção, no cenário de uma economia estruturada com base em estoques de conhecimento, produzidos e disseminados velozmente graças às tecnologias comunicacionais modernas.

Entretanto, apesar da autora destacar o valor econômico adquirido pela informação no começo do século, Ilharco (2003, p. 33) nos lembra que "a informação é um fenômeno diversificado, complexo e penetrante [...] tal como o ser a informação pode ser dita de muitas formas, e essa correlação provavelmente não é acidental." Por possuir um caráter tão múltiplo o conceito de informação constitui-se num dos maiores exemplos de polissemia existentes atualmente, ou como afirmam Wersig e Nevelling (1975 apud PINHEIRO, [2004], p. 02) "é o mais extremo caso de polissemia na comunicação técnica da informação e documentação."

A polissemia que envolve a ideia de informação se deve ao fato dela perpassar todas as práticas humanas. A humanidade se erigiu sob o intercâmbio constante de dados; dados esses que foram sucessiva e ininterruptamente apropriados pelos sujeitos. Da apropriação e manipulação destes pelos sujeitos surge à informação e é baseando-se nela que o ser humano interfere no mundo. A informação inexiste sem um cognoscente, sem uma consciência que a contextualize e dê significado e uso. Assim como a informação depende da consciência humana para existir, o ser humano depende da informação, como matéria prima fundamental, para construir sua humanidade.

Trouxemos, no parágrafo anterior, a ideia de dado - aqui entendido como "uma sequência de símbolos quantificados ou quantificáveis." (SETZER, [2001], p. 01) - porque tal elemento está umbilicalmente ligado à informação. A relação entre ambos é tão próxima que em muitos momentos esses termos chegam a ser tratados como sinônimos perfeitos quando, na verdade, não o são. Dado são todos os elementos - materiais e imateriais - que estão postos no mundo. Esses elementos são informações em potencial e são passíveis de quantificação. A informação possui um caráter marcado pelo qualitativo, pela subjetividade e 
acúmulo de experiências dos sujeitos que entram em contato com os dados e a eles atribuem significados.

Cardoso (1996, p. 72) corrobora nosso pensamento quando afirma que "[...] inexiste a informação independente de sua transmissão ou compartilhamento [...] bem como é impossível um ser humano (na acepção completa da expressão) desconectado da herança cultural comum ao grupo ao qual pertence." Sendo a informação esse fenômeno incapaz de existir fora de um contexto, torna-se fundamental a construção de modelos que ajudem a ampliar nossa compreensão e a fomentar o uso e aproveitamento desse fenômeno tão complexo.

\section{RANGANATHAN E SUAS LEIS}

As Leis da Biblioteconomia, também denominadas de Leis de Ranganathan, nos seus mais de oitenta anos de existência, proporcionaram a base teórica necessária para os trabalhos desenvolvidos por inúmeros profissionais. Essas leis, como veremos a seguir, compõem-se de enunciados simples, porém com um forte significado. As Leis da Biblioteconomia são:

1 Livros são para o uso

2 A cada leitor seu livro

3 A cada livro seu leitor

4 Economize o tempo do leitor

5 A biblioteca é um organismo em crescimento

Em um primeiro momento, essas leis podem parecer até simplórias mas, na verdade, são enunciados fortes e que podem atuar como norteadores das práticas de toda e qualquer biblioteca - e, porque não dizer, de toda e qualquer unidade de informação? - independente de sua localização e/ou público-alvo. Em documento recente sobre a importância dessas leis, afirma-se que "elas continuam sendo um importante mecanismo de ajuda para a união dos valores da biblioteconomia com programas e atividades concretas ${ }^{2}$." (CONNAWAY; FANIEL, 2014, p. 05, Tradução nossa).

A contribuição inicial dessas leis para a Biblioteconomia foi no tocante ao questionamento à prática de priorizar a guarda em detrimento do acesso, ou seja, as leis questionavam o aspecto excessivamente preservacionista que dominava a área até então (TARGINO, 2010). Ranganathan foi dos primeiros a propor uma mudança no foco de atuação da área e, consequentemente, apontou que o valor dos recursos informacionais armazenados nas bibliotecas residia na circulação e uso dos mesmos e não, meramente, na sua posse.

Esse questionamento tão claro de todo um status quo e enunciado de maneira tão simples como o é feito na primeira das cinco leis de Ranganathan, demonstra como ideias

2 "They are still an enormously helpful way to link the values of librarianship with concrete programs and activities". 
aparentemente simples - porém com uma complexidade de execução ímpar, uma vez que mexe com diversas instâncias da biblioteca em si e da sociedade como um todo - são capazes de levar a mudanças verdadeiramente significativas e duradouras, chegando a mudar inclusive a relação de toda uma área consigo mesma e com o mundo que a cerca.

A postura direta e inovadora por nós destacada no tocante a primeira lei se estende a todas as demais. Uma vez que num período em que os usuários não eram o foco, Ranganathan já propunha atender de modo indiscriminado todos os tipos de usuários (segunda lei); direcionar a informação ao público que dela realmente necessitasse e de um modo simples, acessível e facilmente compreensível (terceira e quartas leis) e que a biblioteca deve caracterizar-se pela mudança e constante crescimento e desenvolvimento (quinta lei).

As Leis da Ranganathan são um dos raros exemplos de enunciados de caráter norteador de uma área que foram extremamente vanguardistas em seu próprio tempo e que, mesmo décadas depois, mantém sua coerência e atualidade e também continuam servindo de ponto de partida para movimentos de vanguarda e de ruptura dentro (e fora) da Biblioteconomia. Sobre essa constante e até crescente influência das cinco leis, Connaway; Faniel (2014, p. 05, Tradução nossa) dizem que

As cinco leis forneceram uma poderosa orientação para gerações de bibliotecários. Como escopo para a avaliação de programas, políticas e estratégias de biblioteca, provavelmente não exista um único documento tão conhecido, respeitado e referenciado até os dias de hoje, oitenta anos depois de sua publicação ${ }^{3}$.

As mesmas pesquisadoras destacam em seguida que, devido a sua força, as Leis da Biblioteconomia sofrem os mais variados tipos de adaptação ${ }^{4}$ com vistas a abrangerem outros tipos de mídia e unidades de informação e, portanto, serem mais facilmente incorporadas por outras áreas que também lidam com esse fenômeno.

Ranganathan, provavelmente, não fazia ideia da amplitude que suas afirmações alcançariam no tocante a compreensão, por parte de tantos e tão distintos profissionais da informação, das potencialidades oferecidas pelos recursos informacionais e do trato necessário para atingirem-se tais potencialidades. Os bibliotecários foram os primeiros a espantarem-se com a simplicidade e magnitude desse pensamento e foram também os primeiros a dele tirarem proveito. Hoje, outras áreas também o fazem e acreditamos que ao buscarmos contato com outros modelos utilizados para se pensar a informação - como o de Moody e Walsh, apresentado no tópico seguinte - o ganho, para todos os envolvidos, pode ser significativo.

3 "His five laws have provided powerful guidance for generations of librarians. As a framework for evaluating library programs, policies and strategies, there is probably not a single document as widely known, respected and referenced even today, more than 80 years after its publication".

4 Para uma melhor visão das adaptações sofridas pelas Leis da Biblioteconomia recomendamos a leitura do artigo "A modernidade das cinco leis de Ranganathan”, de autoria de Nice Menezes de Figueiredo. 


\section{AS LEIS DA INFORMAÇÃO DE MOODY E WALSH}

As Leis da Informação idealizadas por Moody e Walsh foram apresentadas, em artigo intitulado Measuring The Value Of Information: An Asset Valuation Approach, na sétima Conferência Europeia de Sistemas, em 1999. O objetivo dos pesquisadores com a elaboração dessas leis foi ampliar a sensibilidade para a informação enquanto ativo econômico e propor uma metodologia que orientasse o planejamento de estratágias para o manejo das tecnologias da informação nas organizações.

O trabalho desenvolvido por Moody e Walsh centra-se na ideia de que a informação é elemento fundamental para que as organizações melhorem seu desempenho no tocante ao trato informacional. A sociedade atual tem na informação um de seus elementos principais, entetanto, esse importante recurso ainda é tratado com certa displicência pelas organizações. Os autores afirmam que se a maior parte das " [...] organizações administrasse suas finanças tão mal quanto administra suas informações, elas, provavelente, já estariam fora dos negócios 5 ." (MOODY; WALSH, 1999, p. 10).

Atualmente, a informação é percebida como insumo fundamental por um número cada vez maior de organizações, entretanto, para que esse insumo seja aproveitado plenamente é fundamental que existam elementos que permitam compreender o modo como ele se manifesta e, assim, viabilizar que as organizações tirem um maior proveito dos recursos informacionais de que dispõem. As leis elaboradas por Moody e Walsh cumprem justamente a função de suprir a lacuna existente no que se refere a mecanismos que permitam avaliar o valor, principalmente econômico, da informação.

As leis da informação, já mencionadas tantas vezes e que desempenham papel tão importante, são:

1 A informação é (infinitamente) compartilhável

$2 \mathrm{O}$ valor da informação aumenta com o uso

3 A informação é perecível

$4 \mathrm{O}$ valor da informação aumenta com a precisão

$5 \mathrm{O}$ valor da informação aumenta quando há combinação de informações

6 Mais informação não é necessariamente melhor

7 A informação não é esgotável

Ao proporem essas 7 leis para análise e compreensão do comportamento da informação, Moody e Walsh expuseram de maneira simples e clara que aqueles que desejam utilizar a informação a fim de obter vantagens competitivas não podem encará-la como os demais ativos. A informação só surtirá efeitos positvos se circular adequadamente, mas para que isso ocorra alguns pontos são fundamentais.

5 "If most organisations managed their finances as badly as their information, they would probably be out of business." 
Informação é poder e, salvo rarissímas exceções, o seu compartilhamento, ao contrário do que ocorre com outros insumos, só amplia seu valor, uma vez que estímula a qualidade e multiplicidade das novas informações produzidas. Entretanto, é fundamental terse em mente que a replicação (e estocagem) excessiva da mesma informação é nociva, uma vez que numa sociedade tão mutante como a atual os conteúdos informacionais mudam rapidamente, ou seja, a informação basilar de ontem pode não ter o mesmo valor hoje.

Analisando rapidamente as leis propostas por Moody e Walsh, vemos que elas centram-se em palavras-chave - "compartilhamento", "precisão" e "uso" - que constituem-se em verdadeiros paradigmas para todos aqueles que trabalham diretamente no trato informacional. Por referirem-se a algumas questões extremamente pertinentes e atuais, tornase importante refletir sobre a aplicabilidade das mesmas em outros contextos - que não o empresarial onde, normalmente, são empregadas - e como elas podem complementar e ser complementadas por outras maneiras de encarar e abordar a informação. É isso que faremos no tópico seguinte, ao buscar estabelecer as diferenças e complementaridades entre as Leis da Informação e as Leis de Ranganathan.

\section{LEIS DE RANGANATHAN E LEIS DA INFORMAÇÃO: PARALELOS E DICOTOMIAS}

As Leis de Ranganathan e as Leis da Informação surgiram em épocas e contextos diferentes visando fornecer elementos para a compreensão do fenômeno informacional. Devido às origens distintas, cada uma delas pauta-se em norteadores diferentes. As Leis de Ranganathan tem um viés um tanto mais social, uma vez que incentivam o uso dos recursos informacionais. Já as Leis da Informação surgiram no cenário de sistemas de informação e buscam chamar a atenção para as questões econômicas relacionadas a esse recurso.

Diante do exposto, a primeira vista, pode parecer que ambos os grupos de leis são antagonistas, mas o fato de chamarem atenção para pontos opostos os torna complementares e de grande valia para a construção de um pensamento plural sobre o trato e uso da informação.

Nota-se ao se contrapor ambos os grupos de leis que as afirmações que as compõem formam uma espécie de discussão onde existem paralelos e dicotomias; aproximações e distanciamentos entre todos as contraposições de enunciados realizadas.

O primeiro ponto de complementaridade aparece no primeiro enunciado de cada grupo de leis. Nas Leis de Ranganathan diz-se que "os livros são para uso" e nas Leis da Informação diz-se que "a informação é (infinitamente) compartilhável”. Ao mesmo tempo em que os enunciados concordam quanto ao fato de que a informação é algo partilhável e passível de ser utilizada, o modo como tal característica é exposta é distinto. Ranganathan é quase que imperativo em sua afirmação, Moody e Walsh apenas dizem que o compartilhamento e por extensão o uso da informação é algo que pode ser realizado quase que de maneira infinita. 
Ainda no que se refere ao pensamento de Moody e Walsh, o segundo enunciado de suas leias diz que "o valor da informação aumenta com o uso". Tal afirmação além de complementar o primeiro enunciado apresenta uma das vantagens do compartilhamento, pois o mesmo aumenta o valor (simbólico, econômico, acadêmico e etc.) da informação, ou seja, é na utilização que reside o valor dos recursos informacionais. Uma informação que esteja meramente estocada, longe daqueles para os quais ela pode atuar como elemento solucionador de questionamentos ou insumo de projetos, não possui valor algum ou possui um valor menos do que aquele que poderia ser alcançado por meio do seu compartilhamento.

Logicamente que em alguns contextos, como o industrial, existem determinadas informações que se divulgadas podem representar a perda de vantagens competitivas mas, na maioria dos casos, disseminar informação agrega valor as instituições que o realizam.

Observa-se ainda que a segunda e terceira Leis de Ranganathan, respectivamente, "a cada leitor seu livro" e "a cada livro seu leitor" vão ao encontro do pensamento de Moody e Walsh quando estes afirmam nas leis número 4 e 6 , respectivamente, que "o valor da informação aumenta com a precisão" e "mais informação não é necessariamente melhor". O que se observa é que tanto as Leis de Ranganathan como as Leis da Informação apontam na mesma direção: a de que selecionar e direcionar tanto informação, quanto usuários é algo benéfico, pois a informação não se constituirá como tal e nem será de fato útil se os usuários que acessarem-na não conseguirem tirar proveito dela, por seu turno os usuários não terão suas necessidades informacionais atendidas se forem tragados pelo excesso de informações.

A prática dos enunciados das leis número 4 e 6 de Moody e Walsh, citadas no parágrafo anterior, também contribui para que o que Ranganathan propõe em sua quarta lei, a saber, "economize o tempo do leitor", seja alcançado. Elaborar serviços de informação que poupem o tempo do leitor passa também por construir sistemas que permitam a associação de informações. Nesse ponto, Moody e Walsh destacam no quinto enunciado de suas leis que "o valor da informação aumenta quando há combinação de informações", ou seja, fornecer informação contextualizada e inserida dentro de uma rede informacional, ao invés de isolada, amplia as possibilidades do usuário encontrar uma resposta satisfatória para suas buscas e constitui-se tanto em desafio como em possibilidade de crescimento para instituições tradicionais no trato informacional.

Há ainda o importante alerta feito pela terceira Lei da Informação. Nela, Moody e Walsh dizem que "a informação é perecível". Esse enunciado se aplica perfeitamente ao mundo dos negócios, onde informações sobre o mercado tornam-se obsoletas e podem prejudicar seriamente uma organização que não busque renovar seu estoque informacional com frequência. Prejuízos advindos da obsolescência informacional também podem acometer unidades de informação, pois elas também carecem de conhecer o contexto em que se inserem e esse contexto inclui características dos usuários, tecnologias da informação, outras unidades de informação, dentre outros. Ou seja, realizar pesquisas de mercado, estudo de usuários, treinamento acerca de TI esporadicamente não é suficiente. Faz-se indispensável que essas e outras atividades concernentes a agregar informações acerca do público e do 
ambiente em que se está inserido sejam realizadas pelas organizações de modo frequente e que primem pela qualidade.

Outro paralelo é o existente entre a quinta lei de Ranganathan "a biblioteca é um organismo em crescimento" e a sétima lei de Moody e Walsh "a informação se multiplica". Ambos os enunciados apontam para o fato de que o conteúdo informacional tem o crescimento como característica e que os profissionais que se propõem a trabalhar com esse recurso devem estar atentos as dinâmicas, cada vez mais mutáveis devido a velocidade e ampliação de alcance proporcionados pelas Novas Tecnologias da Informação, e buscarem preparar-se para lidar com esse crescimento constante.

Acerca disso, Ortega y Gasset (2006) já alertava no começo do século XX que um dos pontos centrais da ação do bibliotecário deveria ser atuar como um filtro, um mediador entre aquele que busca e o turbilhão de informações que o cercam. O que percebe-se pelas palavras de Ortega y Gasset é que a preocupação com o crescimento acelerado da produção informacional está presente nas discussões há um bom tempo. Essa preocupação faz eco no fato de tanto as Leis de Ranganathan quanto as Leis da Informação terem como último enunciado afirmações que reiteram a inevitabilidade do crescimento informacional, crescimento este que não pode ser negligenciado pelos profissionais da informação, devendose, portanto, ter tal característica em mente sempre que sistemas e/ou ambientes de informação forem criados.

\section{CONSIDERAÇÕES FINAIS}

Perceber a importância que a informação possui na sociedade contemporânea é fácil. Ela é o único insumo que pode constituir-se em diferencial tanto no desempenho de grandes corporações como no dia a dia do cidadão comum. Entretanto, não basta ela existir para lograr êxitos, pois como alerta Beal (2007, p. 31) "o uso é a etapa mais importante de todo o processo de gestão da informação [...] Não é a existência da informação que garante melhores resultados numa organização, mas sim o uso, dentro de suas finalidades básicas $[\ldots] "$

Foi buscando otimizar os usos possíveis da informação que, tanto Ranagnathan, quanto Moody e Walsh buscaram elaborar conjuntos de enunciados que, por sua simplicidade e alcance, acabaram constituindo-se em leis. Esses dois conjuntos de leis demonstram que formato, suporte, tecnologia são apenas os meios de apresentação e entrega da informação indispensáveis, mas não absolutos - e que é a informação, ou melhor, o uso da informação que deve nortear as ações dos profissionais que trabalham diretamente com sua gestão.

Combinar as Leis de Ranganathan com as Leis da Informação, de Moody e Walsh, a fim de melhor compreender a informação e suas nuances constitui-se, antes de mais nada, em um esforço para compreender esse fenômeno cuja construção e atribuição de sentidos se dá no plano da subjetividade, mas que cujas implicações no plano social são capazes de mudar os rumos da história. 


\section{REFERÊNCIAS}

BEAL, Adriana. Gestão estratégica da informação: como transformar a informação e a tecnologia da informação em fatores de crescimento e de alto desempenho nas organizações. São Paulo, SP: Atlas, 2007.

CARDOSO, Ana Maria Pereira. Pós-modernismo e informação: conceitos complementares? Perspectivas em Ciência da Informação. Belo Horizonte, MG, v. 1, n. 1, p. 63-79, jan./jun. 1996.

CONNAWAY, Lynn Silipigni; FANIEL, Ixchel M. Reordering Ranganathan: shifting users behaviors, shifting priorities. Ohio, EUA: OCLC, 2014. Disponível em: $<$ http://www.oclc.org/research/publications/library/2014/oclcresearch-reorderingranganathan-2014-overview.html> Acesso em: 01 ago. 2014.

ILHARCO, Fernando. Filosofia da informação: uma introdução à informação como fundação da acção, da comunicação e da decisão. Lisboa: Universidade Católica Editora, 2003.

MOODY, Daniel; WALSH, Peter. Measuring the value of information: an asset valuation approach. In: EUROPEAN CONFERENCE ON INFORMATION SYSTEMS, 7., 1999, Frederiksberg, Dinamarca. Anais... Frederiksberg, Dinamarca: Copenhagen Business School, 1999. p. 1-17.

ORTEGA Y GASSET, José. Missão do bibliotecário. Brasília, DF: Briquet de Lemos Livros, 2006.

PINHEIRO, Lena Vania Pinheiro. Informação: esse obscuro objeto da Ciência da Informação. [2004]. Disponível em: <http://r.duckduckgo.com/l/?kh=1\&uddg=http $\% 3 \mathrm{~A} \% 2 \mathrm{~F} \% 2 \mathrm{Fwww}$. seer.unirio.br\%2Findex.php\%2Fmorpheus $\% 2 \mathrm{Farticle} \% 2 \mathrm{Fd}$ ownload\%2F4108\%2F3759> Acesso em 30 nov. 2014.

ROBREDO, Jaime. Da ciência da informação revisitada aos sistemas humanos de informação. Brasília, DF: Thesaurus, 2003.

SANTILLANA, Giorgio de. O historiador e a teoria da informação. In: COLLOQUE PHILOSOPHIQUE INTERNATIONAL DE RAYAUMONT; 6.; 1962. O conceito de informação na ciência contemporânea. Rio de Janeiro: Paz e Terra, 1970. p. 9-37.

SETZER, Valdemar W. Dado, Informação, Conhecimento e Competência. [2001]. Disponível em: <http://www.ime.usp.br/ vwsetzer/dado-info.html > Acesso em: 30 nov. 2014. 
TARGINO, Maria das Graças. Ranganathan continua em cena. Ciência da Informação. Brasília, DF, v. 39, n. 1, p. 122-124, jan./abr. 2010. Disponível em:

<http://revista.ibict.br/ciinf/index.php/ciinf/article/view/1778/1361> Acesso em: $10 \mathrm{dez}$. 2014.

WERTHEIN, Jorge. A sociedade da informação e seus desafios. Ciência da Informação. Brasília, DF, v. 29, n. 2, p. 71-77, maio/ago. 2000.

Como citar este documento:

SANTOS, Izabel Lima dos. A informação e suas leis: um paralelo entre o pensamento de Ranganathan e 0 de Moody e Walsh. Revista Digital de Biblioteconomia e Ciência da Informação, Campinas, SP, v. 13, n. 3, p. 469-479, set. 2015. ISSN 1678-765X. Disponível em: <http://periodicos.sbu.unicamp. br/ojs/index.php/rdbci/article/view/8635792>. Acesso em: 18 Set. 2015. 